\title{
Improvement of MOR zeolite membranes by using ion beam irradiation
}

\author{
Mikihiro Nomura $^{1 *}$, Daiki Tamashiro ${ }^{1}$, Shogo Sakai ${ }^{1}$, Ryuhei Ono ${ }^{1}$, Abudullah Bukhari ${ }^{1}$ \\ Masaki Sugimoto $^{2}$, Masato Yoshikawa ${ }^{2}$ and Yukichi Sasaki ${ }^{3}$ \\ 1: Department of Applied Chemistry, Shibaura Institute of Technology, 3-7-5 Toyosu, Koto-ku, Tokyo 135-8548, Japan \\ 2: Quantum Beam Science Directorate, Takasaki, Japan Atomic Energy Agency \\ 3: Nano structures Research laboratory, Japan Fine Ceramics Center \\ Fax: 81-3-5859-8160, e-mail: Lscathy@shibaura-it.ac.jp
}

\begin{abstract}
Improving water flux through a zeolite membrane is important in reducing the cost of manufacturing such membranes. Water flux through a mordenite (MOR) zeolite membrane was increased by $84 \%$ by treating it with a novel ion beam irradiation technique that maintained high water permselectivity (1200). Os ions were accelerated in a cyclotron at $490 \mathrm{MeV}$, and a fluence of $3.0 \times 10^{11}$ ions $\mathrm{cm}^{-2}$ was employed for treatment. A calculation using SRIM 2012 showed that the Os ion tracks at $490 \mathrm{MeV}$ should be passed through the MOR zeolite layer. In this study, ion tracks of approximately $\phi 8 \mathrm{~nm}$ were measured on the surface view of the transmission electron microscope (TEM) observations. The single gas permeation of $\mathrm{H}_{2}$ and $\mathrm{N}_{2}$ at room temperature was almost the same before and after irradiation treatment. The ion track pathways through the MOR layer were water permselective assuming that all the permeation change before and after irradiation was due to the ion track paths.
\end{abstract}

Key words: MOR zeolite membrane, dehydration, ion beam irradiation, intercrystalline paths

\section{INTRODUCTION}

Dehydration of isopropyl alcohol (IPA) aqueous solution is important to efficiently produce IPA. Hydrophilic zeolite membranes such as a MOR membrane have been developed for water permselective membranes from alcohol aqueous solution [1]. There are two paths through zeolite membranes [2]. One is the intracrystalline path that allows molecules to pass through the inside of zeolite pores. The other is the intercrystalline path that allows molecules to pass through the outside of zeolite crystals. It is difficult to distinguish whether the permeation differences through the intercrystalline and intracrystalline pathways. In order to compare the permeation characteristics of a membrane are intercrystalline or intracrystalline. To investigate the permeation properties of the membrane and to avoid microstructure differences for the as-made membranes, permeation before and after post-treatments should be compared.

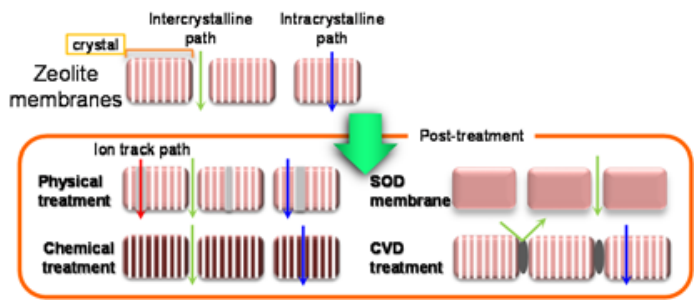

Fig. 1 Schematic diagram for our research concept

Fig. 1 shows our research concept for permeation through zeolite membranes. Post-treatments can be classified into four types. The first is a selective filling technique of the intercrystalline path that uses a chemical vapor deposition (CVD) method [3]. The second is a chemical treatment that partly dissolves zeolite membranes using an alkali or acid solution. The advantage of this chemical treatment is that the dissolution of zeolite membranes can be controlled by changing the chemicals of a solution. Hydrophilic Si components are selectively dissolved from zeolite crystals in a sodium hydroxide solution [4]. The third is a physical treatment in which zeolite membranes are physically damaged. Recently, MFI crystals were treated by ${ }^{238} \mathrm{U}$ irradiation to obtain artificial nanopores in crystals [5]. The fourth involves the use of a non-porous zeolite membrane such as an SOD membrane. The effects of these post-treatments are compared to investigate the permeation mechanism through zeolite membranes. However, in extant literature, no studies related to the use of ion beam irradiation on zeolite membranes as a posttreatment method have been reported. In this study, the effects of ion beam irradiation on hydrophilic MOR zeolite membranes are investigated as a possible physical post-treatment. The permeation mechanism can be discussed by comparing it with the as-made membrane and irradiated membrane.

\section{EXPERIMENTAL}

MOR zeolite membranes were synthesized with MOR seed crystals on porous $\alpha$-alumina disk substrates $(\phi: 13$ $\mathrm{mm}, 150 \mathrm{~nm}$ pore size: Noritake Co.) on the basis of a procedure described in a previous study [1]. The composition of the MOR parent gel was $10 \mathrm{Na}_{2} \mathrm{O}$ : $15 \mathrm{Al}_{2} \mathrm{O}_{3}$ : $36 \mathrm{SiO}_{2}$ : $960 \mathrm{H}_{2} \mathrm{O}$. Crystallization was performed at $180^{\circ} \mathrm{C}$ for $6 \mathrm{~h}$ in a Teflon autoclave.

Ion beam irradiation was performed using ${ }^{192} \mathrm{Os}^{30+}$ ions at $490 \mathrm{MeV}$ with a cyclotron. Irradiation fluence was 1.0 $\times 10^{10}$ ions $\mathrm{cm}^{-2}$ (membrane A) or $3.0 \times 10^{10}$ ions $\mathrm{cm}^{-2}$ (membrane B) and was controlled by changing the 
irradiation period. Current was measured using a Faraday cup before and after irradiation.

Permeation properties through the obtained membranes were evaluated by single gas permeation tests and IPA/water pervaporation (PV). IPA/water PV was employed at $80 \mathrm{wt} \%$ of IPA at $75{ }^{\circ} \mathrm{C}$. The single gas permeation tests were performed by using $\mathrm{H}_{2}$, and $\mathrm{N}_{2}$ at room temperature.

Physical characterizations were employed for X-Ray diffraction (XRD: $2 \theta / \theta, \mathrm{Cu}-\mathrm{K} \alpha$ ), a scanning electron microscope (SEM) and a transmission electron microscope (TEM). XRD measurements were performed using a RINT-Ultima III diffractometer (Rigaku Co.). SEM observations were performed at an acceleration energy of $1 \mathrm{kV}$ by using JEOL JSM-7400F. The membranes microstructures were observed at $200 \mathrm{kV}$ using a TEM (JEM-2010 JEOL). The specimen for TEM observation was prepared using an ion milling method.

\section{RESULTS AND DISCUSSIONS}

3.1 SRIM evaluation through a MOR layer

MOR crystals of a few microns were randomly orientated in the surface view, as shown in Fig. 2 (a). The cross-sectional view is shown in Fig. 2 (b). The intergrowth layer of MOR crystals was found on the porous alumina substrate. The thickness of the MOR layer was approximately $2.6 \mu \mathrm{m}$.
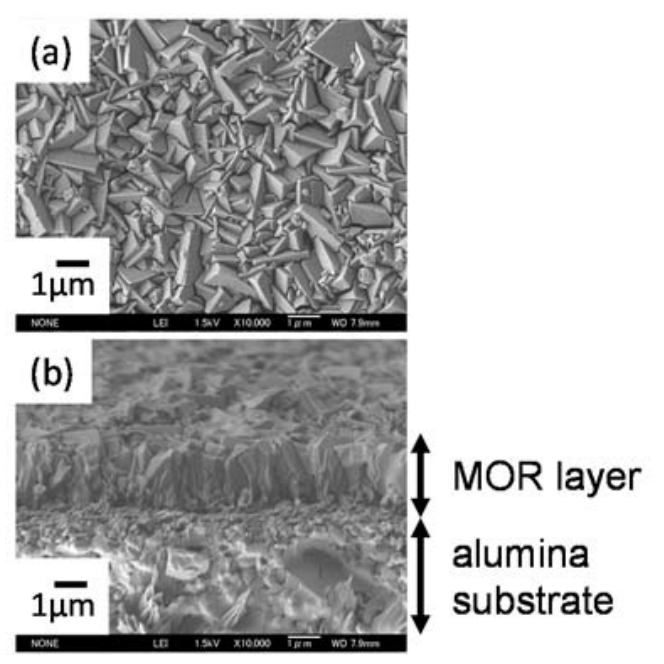

Fig. 2 SEM images for a MOR membrane (a) surface view, (b) cross-sectional view

Next, energy loss of an ion beam irradiation through the MOR zeolite structure was evaluated by using SRIM 2012 [6]. The MOR zeolite density was calculated from the composition for $\mathrm{Si}_{14} \mathrm{Al}_{3} \mathrm{Na}_{3} \mathrm{O}_{34}$ as $1.8 \mathrm{~g} \mathrm{~cm}^{-3}$. Fig. 3 shows the stopping power plotted as a function of depth of the MOR structure of Os ions. The thicknesses of the MOR membranes employed in this study were less than the depth calculated in Fig. 3. Therefore, ions were passed through the MOR layers for all irradiation conditions described in Fig. 3. This trend is similar to results for LTA zeolite structures, shown in the former report [7].

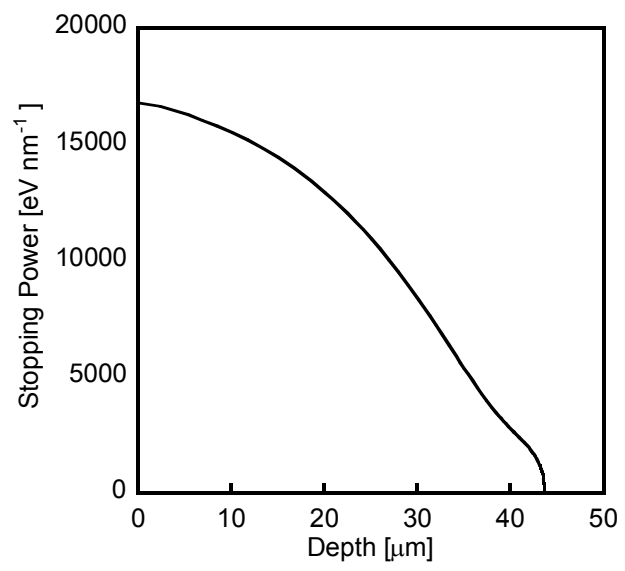

Fig. 3 Stopping power of Os ions through a MOR structure

3.2 MOR membrane preparation on a flat disk substrate MOR membranes were prepared on tube substrates [1]. To investigate permeation properties through ion track paths, MOR membranes were crystallized on flat disks. First, the disk substrate was placed horizontally on the bottom of the autoclave. IPA selectivity through the membrane was 1.0 , indicating that the membrane was not dense. Next, the disk substrate was placed vertically in the autoclave using a home-made Teflon stand. IPA selectivity was over 980 , and the total flux was $0.34 \mathrm{~kg}$ $\mathrm{m}^{-2} \mathrm{~h}^{-1}$. No particles were found on the disk after crystallization. It is important to avoid particle deposition during crystallization by placing the substrate vertically in an autoclave. The permselectivity through the MOR membrane was the similar to that through the membrane prepared on a tube substrate shown in the literature [1].

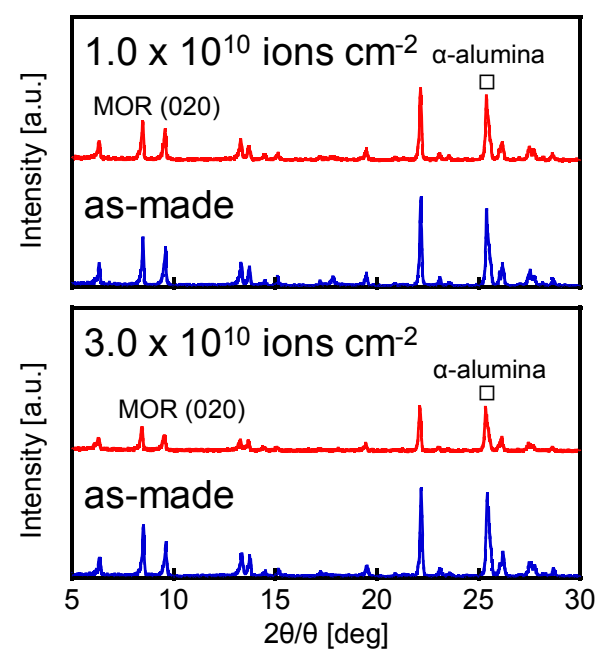

Fig. 4 XRD measurements for the MOR membranes before and after the Os ions irradiation at $1.0 \times 10^{10}$ ions $\mathrm{cm}^{-2}$ and $3.0 \times 10^{10}$ ions $\mathrm{cm}^{-2}$ $\square$ : $\alpha$-alumina 
3.3 Effects of the irradiation on physical properties

Subsequently, irradiation effects on physical properties of the MOR layer were determined. Fig. 4 shows XRD measurements before and after the ion beam irradiation for membranes $A$ and $B$. The peak at $2 \theta / \theta=8.6^{\circ}$ indicates (020) of the MOR structure. The peak at $2 \theta / \theta=25^{\circ}$ indicates the $\alpha$-alumina structure used as a substrate. All peaks of the as-made samples were identified as the MOR structure and $\alpha$-alumina structure. Therefore, we concluded that the MOR zeolite layer was prepared on the $\alpha$-alumina substrates. This is also supported by SEM observations, as shown in Fig. 3. The MOR structure was not completely destroyed by $490 \mathrm{MeV}$ Os ions irradiation at $1.0 \times 10^{10}$ ions $\mathrm{cm}^{-2}$ and $3.0 \times 10^{10}$ ions $\mathrm{cm}^{-2}$. However, XRD peaks of the MOR structure obviously decreased after irradiation at $3.0 \times 10^{11}$ ions $\mathrm{cm}^{-2}$ for the preliminary investigation using a tube MOR membrane (not shown in the Fig.). The effects of irradiation fluence will be discussed later.
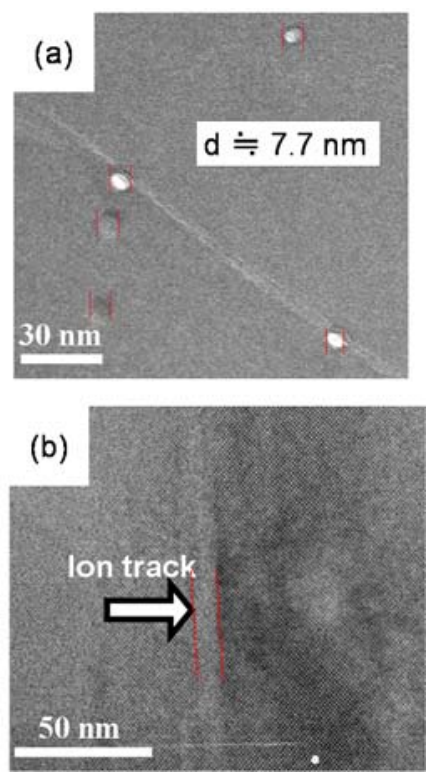

Fig. 5 TEM image of the (a) surface view and (b) cross-sectional view of membrane $\mathrm{B}$ (irradiation fluence: $3.0 \times 10^{10}$ ions $\mathrm{cm}^{-2}$ )

Fig. 5 shows TEM images of the surface and crosssectional views of membrane B. White circles approximately $\phi 7.7 \mathrm{~nm}$ in diameter were found on the surface image shown in Fig. 5 (a). These circles were the ion tracks damaged by Os ion irradiation. The structure in the white circles must not be void. Usually, zeolites are converted to the dense phase by high temperature treatment. The number of white circles was approximately $2.3 \times 10^{10} \mathrm{~cm}^{-2}$ from the low magnification image. This fluence was on the same order of irradiation fluence $\left(3.0 \times 10^{10}\right.$ ions $\left.\mathrm{cm}^{-2}\right)$ measured using a Faraday cup. The straight line can be seen in the cross-sectional view shown in Fig. 5 (b). This line was the ion track of the Os ions. The width of the line was approximately $8 \mathrm{~nm}$, which is almost the same as the circle size in the surface view. If the Os ions were randomly irradiated, $\phi 8 \mathrm{~nm}$ of the ion tracks overlap over $1.0 \times 10^{11}$ ions $\mathrm{cm}^{-2}$ of irradiation fluence. XRD peak reduction by $3.0 \times 10^{11}$ ions $\mathrm{cm}^{-2}$ of irradiation can be explained by the overlapping of the ion tracks. The sizes of the ion beam spots and irradiation fluence to poly (methylphenilsilane) (PMPS) were numerically discussed in a previous study [9]. The trend of the gel fraction of PMPS changed at approximately $10^{11}$ ions $\mathrm{cm}^{-2}$ of irradiation fluence based on the assumption that the ions are randomly arranged on the surface. PMPS gel and MOR zeolites are different materials. However, the effects of irradiation can be geometrically similar.

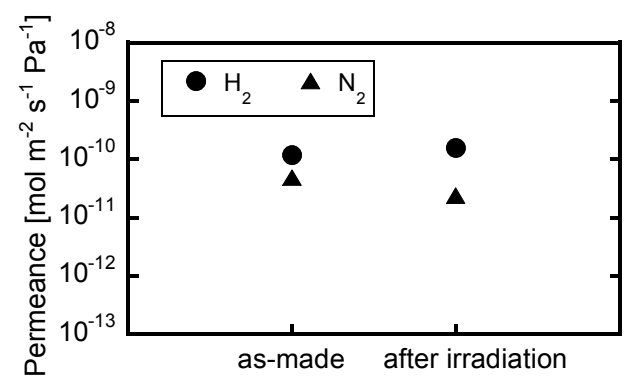

Fig. 6 Single gas permeance through membrane B
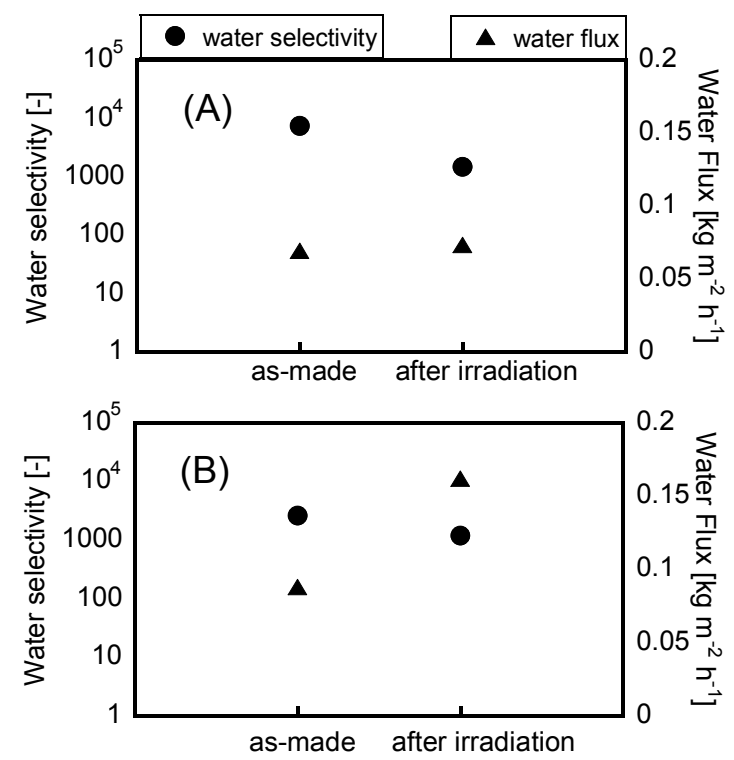

Fig. 7 IPA/water PV results before and after irradiation for the MOR membranes

(A) $1.0 \times 10^{10}$ ions $\mathrm{cm}^{-2}$, (B) $3.0 \times 10^{10}$ ions $\mathrm{cm}^{-2}$

3.4 Effects of the irradiation on permeation properties

Permeation properties were investigated by gas permeation tests and PV measurements before and after irradiation. Ion tracks must be the artificial intracrystalline paths through the MOR membrane. Fig. 6 shows the single gas permeation tests through membrane $\mathrm{B}\left(3.0 \times 10^{10}\right.$ ions $\left.\mathrm{cm}^{-2}\right)$. The initial $\mathrm{N}_{2}$ permeance was $4.8 \times 10^{-11} \mathrm{~mol} \mathrm{~m}^{-2} \mathrm{~s}^{-1} \mathrm{~Pa}^{-1}$, and it decreased to $2.4 \times$ $10^{-11} \mathrm{~mol} \mathrm{~m}^{-2} \mathrm{~s}^{-1} \mathrm{~Pa}^{-1}$ after irradiation. The $\mathrm{H}_{2}$ permeance slightly increased through irradiation. However, both differences were not significant. Therefore, we consider that the permeance of an inert gas such as $\mathrm{H}_{2}$ and $\mathrm{N}_{2}$ did 
not change by irradiation at $3.0 \times 10^{10}$ ions $\mathrm{cm}^{-2}$. The kinetic diameter of $\mathrm{H}_{2}$ and $\mathrm{N}_{2}$ are $0.29 \mathrm{~nm}$ and $0.36 \mathrm{~nm}$, respectively. These diameters are much smaller than those of the white circles shown in Fig. 5 (a). If the white circles were void, $\mathrm{H}_{2}$ permeance and $\mathrm{N}_{2}$ permeance should have increased sharply after irradiation. Therefore, these single gas permeation results support our claim that the white circles are not voids.

Fig. 7 shows the IPA/water PV results through membranes A and B. Initial water permselectivities through the membranes were excellent (above 1,000), and similar. Recently, a combination of a water permselective membrane and a distillation column had been proposed as a method to improve energy efficiency. Water permselectivity of $20-150$ was high enough for improvement [8]. Initially, water selectivity was 7600 with $0.069 \mathrm{~kg} \mathrm{~m}^{-2} \mathrm{~h}^{-1}$ of the flux through membrane A and 2700 with $0.088 \mathrm{~kg} \mathrm{~m}^{-2} \mathrm{~h}^{-1}$ for membrane B. There was no significant permselectivity difference found after irradiation at $1.0 \times 10^{10}$ ions $\mathrm{cm}^{-2}$. Total flux improved by approximately $84 \%$ by keeping the high water selectivity above 1,200 through membrane B. The flux of IPA component increased from $3.3 \times 10^{-5} \mathrm{~kg} \mathrm{~m}^{-2} \mathrm{~h}^{-1}$ to $1.3 \times$ $10^{-4} \mathrm{~kg} \mathrm{~m}^{-2} \mathrm{~h}^{-1}$ through irradiation. The flux of the water component changed at $7.4 \times 10^{-2} \mathrm{~kg} \mathrm{~m}^{-2} \mathrm{~h}^{-1}$. If all flux difference was due to the new paths made by the Os ion tracks, the water permselectivity through the new paths was calculated as 730. This shows that the paths outside the MOR crystals were water permselective. The kinetic diameter of water is $0.26 \mathrm{~nm}$, which is much smaller than the size of the Os ion tracks (ca. $8 \mathrm{~nm}$ ), as shown in Fig. 5 (a).

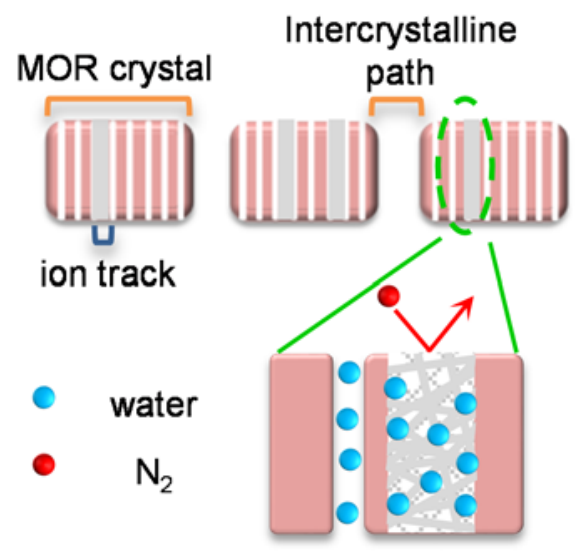

Fig. 8 Permeation image through the ion track made by Os ion irradiation

Considering the gas permeation and PV results, we propose that the ion tracks were not void, and that the pore wall should exhibit hydrophilic properties. Usually, the hydrophilic property of a silica or alumina surface can be explained by hydroxyl groups at the surface. However, irradiation was performed in a high vacuum condition without water vapor. One possible explanation is that the ion track surface was hydrated after the sample was removed from the vacuumed apparatus. Fig. 8 shows the physical image of the MOR membrane after irradiation. The ion track path was described as a net structure. The MOR structure must change to a denes structure at the ion track columns. The density of MOR is $1.8 \mathrm{~g} \mathrm{~cm}^{-3}$, which is much smaller than that of silica $\left(2.2 \mathrm{~g} \mathrm{~cm}^{-3}\right)$ or alumina $\left(4.0 \mathrm{~g} \mathrm{~cm}^{-3}\right)$. Therefore, there was a space in the ion track paths. However, gas permeation of $\mathrm{H}_{2}$ and $\mathrm{N}_{2}$ did not change by irradiation, as shown in Fig. 6. These paths must be water permselective, and water was adsorbed in the void during the gas permeation test.

\section{CONCLUSIONS}

Water permselective MOR membranes were treated by high energy Os ion irradiation. The initial water selectivity was 2700 with $0.088 \mathrm{~kg} \mathrm{~m}^{-2} \mathrm{~h}^{-1}$ of the total flux. Total flux was improved to $0.162 \mathrm{~kg} \mathrm{~m}^{-2} \mathrm{~h}^{-1}$ by maintaining a water selectivity of 1200 by Os ion irradiation at $3.0 \times 10^{10}$ ions $\mathrm{cm}^{-2}$. The physical structure measured by XRD did not change by the irradiation. The size of ion track damage was measured approximately $\phi$ $8 \mathrm{~nm}$ by TEM surface observation.

\section{REFERENCES}

[1] M. Matsukata et al., J. Membr. Sci., 316 (2008) 18-27.

[2] M. Nomura et al., J. Membr. Sci., 187 (2001) 203-212.

[3] M. Nomura et al., Ind. Eng. Chem. Res., 36 (1997) 4217-4223.

[4] M. Ogura et al., Applied Catal. A., 219 (2001) 33-43

[5] V. Valtchev et al., J. AMERICAN Chem. Soc., 133 (2011) 18950-18956

[6] http://www.srim.org/

[7] Y. Sasaki et al., AMTC Lett., 2 (2010) 258-259

[8] M. Matsukata, Petrotech, 33 (2010) 402-406 [in Japanese]

[9] S. Seki et al., Macromolecules, 38 (2005) 1016410170

\section{ACKNOWLEDGEMENT}

This work has been partially supported by Development of Fundamental Technologies for Green and Sustainable Chemical Processes (Green and sustainable chemistry/fundamental development of ordered-nanoporous membranes for highly-refined separation technology).

(Received October 22, 2012; Accepted June 12, 2013) 